146 Wasserleitungswasser zu Augsburg. - Schwefelthermen der Pyrenäen.

Wasser der Wasserleitung zu Angsburg. - J. W inckel mann hat das Wasser der Wasserleitung zu Augsburg untersucht und fand in 100,000 Th. Chlor $=0,35$, Schwefelsäure $=1,67$, Kalk $=9,95$, Magnesia $=3,20$, Salpetersäure $=0,33$, organische Substanz $=1,40$. Diese Bestandtheile reihen das Wasser zu den kalkreicheren Quellen, wie sie in der Kalkformation häufig geboten werden. Das Wasser wird aus einem in der Hochebene des Lechfeldes angelegten Tiefbrunnen entnommen, mitten in einem der Stadt Augsburg gehörigen Walde. Die Mischung ist diejenige reiner Quellen und können ebenso hier dieselben unterirdisch auf treten, W inckelmann bezeichnet es als Grundwasser; letzteres zeigt sich aber fast überall reichlicher mit Bestandtheilen der Oberfläche der Erde verunreinigt.

$R d t$. \title{
weiss? \\ Warum werden gewisse Schwefelthermen der Pyrenäen
}

1) Schwefelquellen, welche zu Bädern benutzt und mit keinem Wasser, welches Sauerstoff und Kohlensäure gelöst enthält, gemischt werden, bleiben unverändert, d. $h$, es tritt keine Weissfärbung ein. Dieses ist bei allen Sohwefelthermen Luchon.

2) der Pyrenäen der Fall, besonders bei der zu Bagnères de

Wird Schwefelwasser mit kaltem Wasser gemischt, so tritt nicht sofort ein Weisswerden ein, sondern später, weil sich erst ein Polysulfür bilden muss. Dieses war der Fall zu Bagnères de Luchon mit der Source blanche, wo sich gewöhnliches kaltes Wasser mit der warmen Schwefelquelle mischte.

Mischt sich wenig Wasser, welches Luft gelöst enthält, mit der Schwefelquelle, so bildet sich wohl ein Polysulfür, aber es tritt kein Weisswerden ein. Dieses ist zu beobachten zu Bagnères, wo das Wasser der Fischteiche Polysulfür enthält und nicht weiss wird. Ein Theil Schwefel entweicht als $\mathrm{H}^{2} \mathrm{~S}$, während der andere in $\mathrm{H}^{2} \mathrm{SO}^{4}$ übergeht.

Wird der Schwefelquelle eine grosse Menge Wasser, welches Sanerst off und Kohlensäure gelöst enthält, zugesetzt, so geht das Wasser in schwefelwasserstoffhaltiges über.

Wenn künstliche Schwefelbäder gemacht werden, in welchen der Schwefelgehalt den der natürlichen Schwefelbäder nicht übersteigt und Polysulfüre genommen worden sind, so ist keine Säure zuzusetzen, weil kohlensäurehaltiges kaltes Wasser genügt, um es weiss zu machen.

Die Zersetzung der Monosulfüre drückt Filhol durch folgende Gleichung aus:

oder vielmehr

$$
2 \mathrm{Na}^{2} \mathrm{~S}+\mathrm{CO}^{2}+\mathrm{H}^{2} \mathrm{O}=\mathrm{Na}^{2} \mathrm{CO}^{3}+\mathrm{Na}^{2} \mathrm{~S}+\mathrm{H}^{2} \mathrm{~S},
$$

$$
2 \mathrm{Na}^{2} \mathrm{~S}+\mathrm{CO}^{2}+\mathrm{H}^{2} \mathrm{O}=\mathrm{Na}^{2} \mathrm{CO}^{3}+2 \mathrm{NaHS} .
$$

